\title{
Ultramorphology and dentine permeability changes induced by prophylactic procedures on exposed dentinal tubules in middle dentine
}

\author{
Salvatore Sauro ${ }^{1}$, Timothy F Watson ${ }^{2}$, Ian Thompson ${ }^{3}$
}

\begin{abstract}
${ }^{1} \mathrm{BDH}, \mathrm{PhD}$, Biomaterials, Biomimetics \& Biophotonics Research Group (B3), King's College London Dental Institute, Guy’s, King's College and St Thomas' Hospitals, London, United Kingdom

${ }^{2}$ BSC, BDS, PhD, FDS, professor and chairman, Biomaterials, Biomimetics \& Biophotonics Research Group (B3), King's College London Dental Institute, Guy's, King's College and St Thomas' Hospitals, London, United Kingdom

${ }^{3} \mathrm{PhD}$, senior lecturer, Biomaterials, Biomimetics \& Biophotonics Research Group (B3), King's College London Dental Institute, Guy's, King's College and St Thomas' Hospitals, London, United Kingdom
\end{abstract}

Correspondence:

Biomaterials, Biomimetics \& Biophotonics

King's College London Dental Institute

Guy's, King's College and St Thomas' Hospitals

Floor 17 Guy's Tower

London, SE1 9RT

England

salvatore.sauro@kcl.ac.uk

Received: $13 / 11 / 2010$

Accepted: 16/01/2011

Sauro S, Watson TF, Thompson I. Ultramorphology and dentine permeability changes induced by prophylactic procedures on exposed dentinal tubules in middle dentine. Med Oral Patol Oral Cir Bucal. 2011 Nov 1;16 (7):e1022-30.

http://www.medicinaoral.com/medoralfree01/v16i7/medoralv16i7p1022.pdf

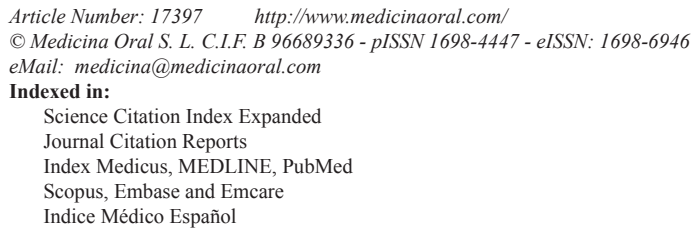

\begin{abstract}
Objectives: The purpose of this study was to evaluate the changes in dentinal permeability (i.e. hydraulic conductance) after prophylactic treatments performed using prophy-powders with air-polishing system or prophy-pastes on exposed middle dentine. The changes in dentine morphology were evaluated by SEM.

Study design: Commercial prophylactic pastes and air-polishing powders were tested in this study. Dentine discs from human third molars were used to study the quantitative reduction of the dentine permeability under simulated pulpal pressure $\left(20 \mathrm{~cm} \mathrm{H}_{2} \mathrm{O}\right)$. Further specimens were gold-coated and analysed using observed a SEM.

Results: The results of this study showed different dentine permeability redaction based on the type of product employed (i.e. prophylactic paste or air-polishing powders). The use of Sylc bioactive glass and sodium bicarbonate were the most effective in reducing dentine permeability of the specimens. However, the air-polishing procedures performed with Sylc bioactive glass created a dentine surface devoid of exposed dentinal tubules due to the presence of a compact multilayered smear layer. Colgate Sensitive Pro-Relief and Nupro NU-Solution reduced the dentine permeability up to $69.8 \%$ and $66.9 \%$ respectively.

Conclusion: Although all the tested products are able to statistically reduce dentine permeability, Sylc bioactive glass is an innovative and effective product which completely occludes the dentinal tubules during prophylactic procedures of air-polishing.
\end{abstract}

Key words: Prophylactic pastes. 


\section{Introduction}

The clinical symptoms of dentine hypersensitivity $(\mathrm{DH})$ is commonly reported during the clinical practice, in particular, subsequent to non-surgical periodontal therapy performed with sonic and manual instruments due to the removal of the thin layer of cementum in the cervical region and along the root surface (1-5). Dentine hypersensitivity is also induced by the enamel loss and/or the gingival root surface abrasion caused by the erosion, abfraction or gingival recession (6-7).

The hydrodynamic theory proposed by Brännström et al, (8) states that thermal, evaporative, tactile, osmotic or chemical stimuli induce the movement of fluid within open dentine tubules $(9,10)$. The movement of the intratubular fluid activates mechanoreceptor nerves, eliciting sharp pain and discomfort which may not be ascribed to any other form or dental defect or pathology $(8,9)$.

Based on the principles of the hydrodynamic theory it has been possible to establish a consistent correlation between fluid flow and the physical occlusion of dentine tubules to evaluate the effects of dentine desensitizes. Indeed, the concept behind this method is that any substance able to obliterate the dentinal tubules and reduce the movement of the intratubular fluid may be suitable for the treatment of $\mathrm{DH}(8,10,11)$. Air polishing as a prophylaxis technique has become very popular with specialists in preventive dentistry as alternative to rotary-rubber instruments (12-15). Furthermore, these systems might also be used for enamel cleaning prior to pit and fissure sealing or orthodontic bracket bonding and in the treatment of root surfaces during nonsurgical periodontal therapy as a valid alternative to hand, sonic and ultrasonic scalers $(16,17)$.

Although prophylactic measures performed with po-lishing rubber cup (PRC) or air-polishing systems (AP) showed to be able to reduce the intratubular fluid flow when applied on deep dentine (18), there is little information on the effects of these treatments when applied in different morphological and working parameters.

The purpose of this study was to evaluate the changes in dentinal permeability (i.e. hydraulic conductance) after prophylactic treatment performed using prophy-powders with a 4-bar air-polishing system or prophy-pastes used with PRC applied on exposed middle dentine. The ultra-morphological changes induced by these experimental treatments when applied on middle dentine were evaluated by using scanning electron microscopy (SEM).

\section{Materials and Methods}

-Specimen preparation for dentine permeability

Thirty human third molars from patients (aged 20-40 years) which were extracted for surgical reasons were collected and stored in deionised water $(\mathrm{pH} 7.4)$ at $4{ }^{\circ} \mathrm{C}$ for the experiments that were conducted within one month of extraction. Protocols were reviewed and approved by the Ethics Committee of the Academic Health Science Centre at King's College London, including informed consent for tissue use in research. Dentine segments were obtained by first removing the roots $1.5 \mathrm{~mm}$ beneath the cementum-enamel junction (CEJ) using a slow-speed water-cooled diamond saw (Labcut, Agar Scientific, Stansted, UK). The occlusal enamel was removed with a parallel cut to expose the middle dentine. Pulpal tissue was carefully removed from the exposed pulp chamber without crushing the pre-dentine surface by using thin tissue forceps. A pincer-type caliper was used for measuring the remaining dentine thickness (RDT) from the surface to the highest pulpal horns (1.2 $\pm 0.1 \mathrm{~mm})$. Each tooth section was positioned on a Perspex $^{\mathrm{TM}}$ platform $(2 \mathrm{~cm} \times 2 \mathrm{~cm} \times 0.5 \mathrm{~cm})$ (Perspex Distributions Ltd., London, UK) that was perforated by an 18 gauge stainless steel tube using cyanocrylate adhesive (ROCKET Heavy DVA, Corona, CA, USA). Each specimen was connected to a hydraulic fluid filtration system able to deliver a simulated pulpal pressure of 20 $\mathrm{cm}$ H2O. A modified split-chamber device was used to allow the standardization of exposed dentine area for fluid filtration by using pairs of rubber "O" rings with an internal diameter of $0.6 \mathrm{~cm}$ (Area: $0.38 \mathrm{~cm}^{2)}$ (Fig. 1). A $25 \mu \mathrm{L}$ capacity micro-capillary tube (Microcaps, Fisher Scientific, Atlanta, GA, USA) was horizontally positioned between the pressure reservoir and the crown segment (Fig. 1). The linear displacement of an air bubble inside the micro-capillary tube indicated the volume displacement which is converted into a measure of the hydraulic conductance. The linear displacement of the

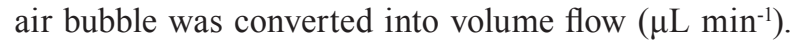
For each specimen, fluid flow across the dentine discs were then transformed into hydraulic conductance (Lp) $\left(\mu \mathrm{Lmin}^{-1} \mathrm{~cm}^{-2} \mathrm{~cm} \mathrm{H}_{2} \mathrm{O}^{-1}\right)$, by dividing the fluid flow $(\mu \mathrm{L}$ min-1) by the exposed dentine surface area $\left(\mathrm{cm}^{2}\right)$ and the water pressure $\left(\mathrm{cm} \mathrm{H}_{2} \mathrm{O}\right.$, i.e. $\left.20 \mathrm{~cm} \mathrm{H}_{2} \mathrm{O}\right)(19,20)$. -Experimental design for dentine permeability

A homogeneous smear layer was created on each dentine surface using a 320-grit SiC abrasive paper for 25 s. Subsequently, the Lp was measured to evaluate the minimum permeability of each specimen. The smear layer was then removed, treating the dentine surface using $37 \%$ orthophosphoric acid solution $\left(\mathrm{H}_{3} \mathrm{PO}_{4}\right)$ for 30 sec (PA). Subsequently, the dentine surface was copiously water-rinsed and the Lp was measured in order to obtain the highest permeability (Lp $\max =100 \%$ was arbitrarily assigned). Lp $100 \%$ permits evaluation 


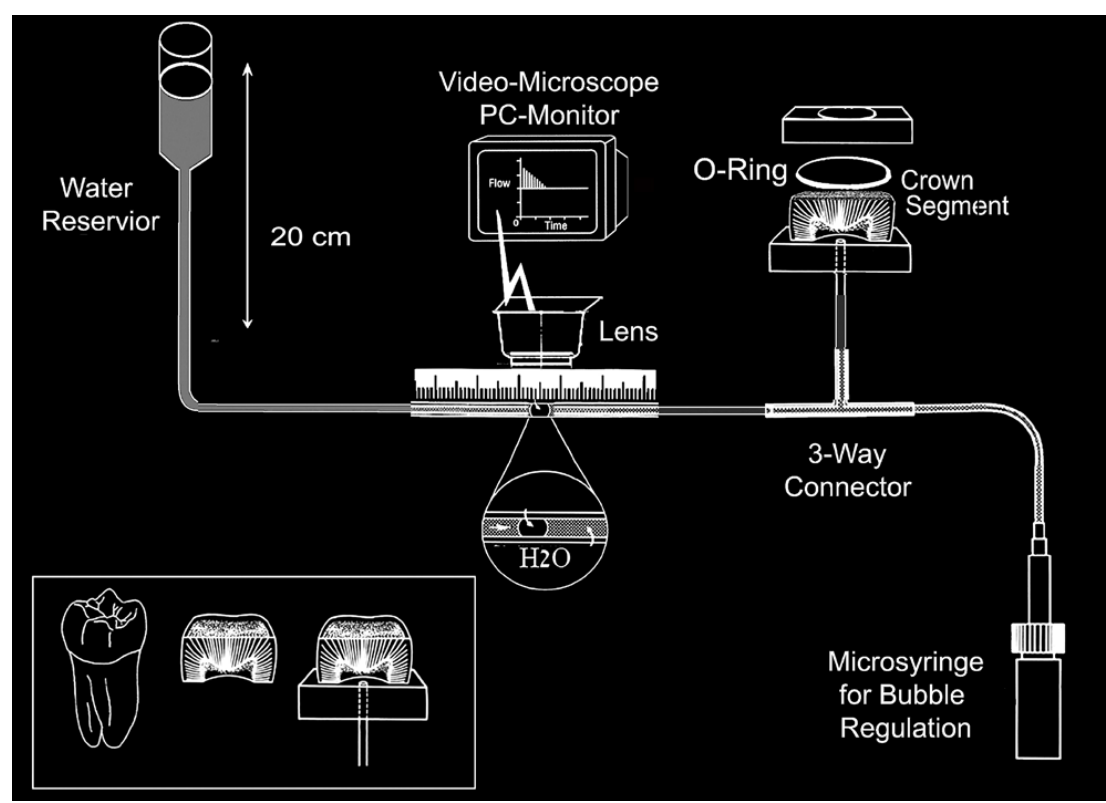

Fig. 1. Scheme depicting the creation of crown segments, the attachment to Perplex and how fluid permeability was measured under $20 \mathrm{~cm} \mathrm{H}_{2} \mathrm{O}$ pressure.

of modifications in dentinal permeability following the test treatments.

Evaluations of dentine permeability were performed by measurement of convective fluid flow through each crown segment under $20 \mathrm{~cm} \mathrm{H}_{2} \mathrm{O}$ of water pressure for $3 \mathrm{~min}$ in triplicate. This sequence was repeated three times for each specimen and averaged to calculate a single mean value. This mean value was then averaged for all specimens in each treatment group to obtain the dentine permeability (Lp). All treatments were applied on wet dentine surface $(18,20)$.

The list of products used in this study, the composition and the application mode are shown in Table 1. The airpolishing system (AP) used to jet-spray the different prophy-powders of this study was the Aquacut Quattro (VELOPEX INTERNATIONAL, London, UK) working at air pressure of 4 bar $(400 \mathrm{MPa})$ and a distance of $5 \mathrm{~mm}$.

Statistical analyses were performed using SPSS 16.0 (SPSS Inc. Chicago, IL, USA) program. The means and standard deviations of each group were calculated from $\mathrm{Lp} \%$ obtained from the treatments. Statistically significant differences were identified among the groups by ANOVA $(\mathrm{P}<0.001)$. Fisher's least significant difference (LSD) test was used to isolate and compare the significant differences $(\mathrm{P}<0.05)$ between the groups.

-Scanning electron microscopy (SEM)

Twelve recently extracted human molars were used for SEM investigation. Dentine slices were obtained from deep-coronal dentine of each tooth using a slow-speed water-cooled diamond saw (Labcut, Agar Scientific, UK). They were randomly divided into 6 groups of 4 slices each for examination with SEM. Dentine slices were polished using a 320 grit $\mathrm{SiC}$ abrasive paper to compose a standardized smear layer. The specimens were submitted to the same experimental treatment design as previously described in dentine permeability evaluation section.

The specimens from each group were dried and then mounted on aluminium stubs with carbon cement. They were sputter-coated with gold (SCD 004 Sputter Coater; Bal-Tec, Vaduz, Liechtenstein) and viewed using a scanning electron microscope (SEM) (S-3500; Hitachi, Wokingham, UK) with an accelerating voltage of $15 \mathrm{kV}$ and a working distance of $14 \mathrm{~mm}$ at increasing magnifications from $100 \mathrm{X}$ to $2500 \mathrm{X}$.

\section{Results}

The results of this study showed that all the tested products reduced the dentine permeability, compared to the maximum fluid flow of PA-etched dentine (Table 2). The application of $37 \% \mathrm{H}_{3} \mathrm{PO}_{4}$ to the dentine surface caused the exposure of dentinal tubules (Fig. 2.A) and the measure of permeability was arbitrarily considered to be $100 \%$; each $\mathrm{H}_{3} \mathrm{PO}_{4}$-treated dentine was considered as its own control of specimen after each desensitizing treatment tested in this study (18).

Although Sylc bioactive glass ( $\mathrm{P} \% 11.2 \%$ ) showed statistically higher permeability reduction compared to Prophy-Jet sodium bicarbonate ( $\mathrm{P} \% 19.7 \%$ ), these to prophy-powders resulted significantly most effective than the other treatments. The use of EMS Perio powder applied to exposed dentine induced a reduction of the dentine permeability up to $68.8 \%$. SEM investigation 
Table 1. Products used in this study, composition and application mode.

\begin{tabular}{|c|c|c|c|}
\hline Treatments (acronym) & Manufacturing & Components & Application mode \\
\hline $\begin{array}{l}\text { Sylc bioactive glass }{ }^{\circledR} \\
\text { Powder }\end{array}$ & $\begin{array}{l}\text { Sylc, OSspray ltd, } \\
\text { Cambridge, UK }\end{array}$ & $\begin{array}{l}\text { Bioactive glass } \\
\left(\mathrm{SiO}_{2}, \mathrm{Na}_{2} \mathrm{O}, \mathrm{CaO} \quad \mathrm{P}_{2} \mathrm{O}_{5}\right)\end{array}$ & $\begin{array}{l}\text { Air-polishing operated in a } \\
\text { Prophyflex air-polishing device } \\
\text { (Velopex) at a distance of } 5 \mathrm{~mm} \\
\text { for } 15 \mathrm{~s} \text {. }\end{array}$ \\
\hline $\begin{array}{l}\text { Sylc bioactive glass }{ }^{\circledR} \\
\mathrm{H}_{2} \mathrm{O}\end{array}$ & $\begin{array}{l}\text { Sylc, OSspray ltd, } \\
\text { Cambridge, UK }\end{array}$ & $\begin{array}{l}\text { Bioactive glass } \\
\left(\mathrm{SiO}_{2}, \mathrm{Na}_{2} \mathrm{O}, \mathrm{CaO} \quad \mathrm{P}_{2} \mathrm{O}_{5}\right) \\
\text { Deionized water }\end{array}$ & $\begin{array}{l}\text { Applied to dentin using a slow- } \\
\text { speed handpiece with a } \\
\text { prophylaxis angle attachment } \\
\text { angle and rotating rubber cup } \\
\text { for } 30 \mathrm{~s}\end{array}$ \\
\hline $\begin{array}{l}\text { Cavitron } ₫ \text { Prophy-Jet }{ }^{\circledR} \\
\text { sodium bicarbonate }\end{array}$ & $\begin{array}{l}\text { Dentslpy corp., } \\
\text { London, UK }\end{array}$ & sodium bicarbonate $(\mathrm{NaHCO} 3)$ & $\begin{array}{l}\text { Air-polishing operated in a } \\
\text { Prophyflex air-polishing device } \\
\text { (Velopex) at a distance of } 5 \mathrm{~mm} \\
\text { for } 15 \mathrm{~s} \text {. }\end{array}$ \\
\hline AIR-flow ${ }^{\circledR}$ powder PERIO & $\begin{array}{l}\text { EMS corp., } \\
\text { Nyon } \\
\text { Swizerland }\end{array}$ & Amino-acid-glycine & $\begin{array}{l}\text { Air-polishing operated in a } \\
\text { Prophyflex air-polishing device } \\
\text { (Velopex) at a distance of } 5 \mathrm{~mm} \\
\text { for } 15 \mathrm{~s} \text {. }\end{array}$ \\
\hline $\begin{array}{l}\text { Colgate }{ }^{\circledR} \text { Sensitive Pro- } \\
\text { Relief }^{\mathrm{TM}}\end{array}$ & $\begin{array}{l}\text { Colgate Palmolive, } \\
\text { New York, NY }\end{array}$ & $\begin{array}{l}\text { Hydrated silica, calcium carbonate, } \\
\text { glycerin, } 8 \% \text { arginine, water, bicarbonate, } \\
\text { flavor, cellulose gum, sodium saccharin, } \\
\text { FD\&C blue no. } 1 \text { (CI 42090) }\end{array}$ & $\begin{array}{l}\text { Applied to dentin using a slow- } \\
\text { speed handpiece with a } \\
\text { prophylaxis angle attachment } \\
\text { angle and rotating rubber cup } \\
\text { for } 30 \mathrm{~s}\end{array}$ \\
\hline $\begin{array}{l}\text { NUPRO } ® \text { NUSolutions }{ }^{\mathrm{TM}} \\
\text { Prophy Paste }\end{array}$ & $\begin{array}{l}\text { Dentslpy corp., } \\
\text { London, UK }\end{array}$ & $\begin{array}{l}\text { Hydrated silica, glycerin, water, } \\
\text { bicarbonate, flavor, cellulose gum, sodium } \\
\text { saccharin and bioactive glass NovaMin } \AA\end{array}$ & $\begin{array}{l}\text { Applied to dentin using a slow- } \\
\text { speed handpiece with a } \\
\text { prophylaxis angle attachment } \\
\text { angle and rotating rubber cup } \\
\text { for } 30 \mathrm{~s}\end{array}$ \\
\hline
\end{tabular}
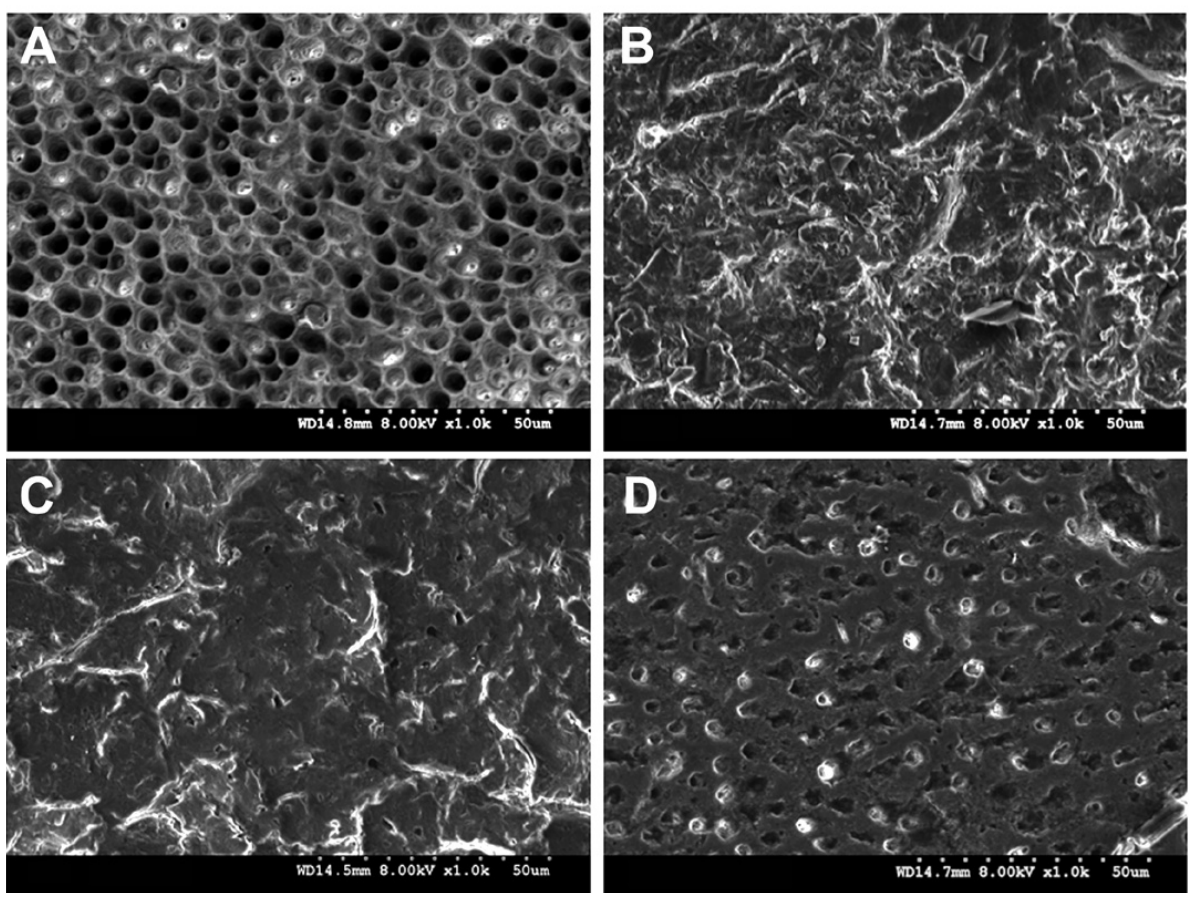

Fig. 2. 1000X SEM micrographs of dentine surfaces air-polished using the prophy-powders tested in this study. A) shows the effects of $\mathrm{H}_{3} \mathrm{PO}_{4}$ on the dentine surface resulting in completely opened dentinal tubules. B) shows the effects of Sylc bioactive glass powder on the dentine surface. This procedure creates the multilayered smear layer that occludes the dentinal tubules. The pictures $\mathbf{C}$ ) shows the effects of Prophy-Jet sodium bicarbonate powder on the dentine surface showing how this procedure also created a smear layer that covers the dentine surface and occludes the dentinal tubules. D) shows the effects of EMS Perio powder on the dentine surface resulting in completely or partially opened tubules. 
supported the permeability results showing that the airpolishing procedures performed on dentine using Sylc bioactive glass (Fig. 2.B) and bicarbonate (Fig. 2.C) occluded the dentinal tubules by forming a smear layer on the dentine surface.

The dentine surface air-polished using EMS Perio Powder showed the presence of dentinal tubules characterized by an altered morphology and only partially occluded (Fig. 2.D). However, the SEM investigation also showed that some of the tubules remained open (Fig. 4.A). The bioactive glass mixed with water and applied using a rotatory rubber cup reduced the dentine permeability up to $81.1 \%$ resulting statistically more effective than the other prophy-pastes; no statistical difference was observed when compared to the permeability reduction induced by sodium bicarbonate applied with the air-polishing device (Table 2).
SEM investigation showed that the use of Sylc bioactive glass $/ \mathrm{H}_{2} \mathrm{O}$ as prophy-paste was suitable for the occlusion of the dentinal tubules with the formation smear plugs inside the dentinal tubules (Fig. 3.A, 4.B).

Colgate Sensitive Pro-Relief reduced the dentine permeability of the $\mathrm{H}_{3} \mathrm{PO}_{4}$-treated dentine up to $30.2 \%$. The SEM investigation showed that Colgate Sensitive Pro-Relief was able to reduce the diameter of the lumen of the tubules (Fig. 3.C, 4.C).

NUPRO Solution Prophy Paste reduced the dentine permeability up to $66.9 \%$ showing a dentine surface that was partially covered with small smear layer-like debris (Fig. 3.B). However, at higher magnifications it was possible to observe that the dentinal tubules were still open or only partially obliterated (Fig. 4.C).

Table 2. Dentine permeability of the tested products.

\begin{tabular}{|c|c|c|c|}
\hline Product & $\begin{array}{c}\text { Max P\% } \\
\left(\mu \mathrm{Lmin}^{-1} \mathrm{~cm}^{-2} \mathrm{~cm} \mathrm{H}_{2} \mathrm{O}^{-1}\right)\end{array}$ & $\begin{array}{c}\text { Treatment } \mathrm{P} \% \\
\left(\mu \mathrm{Lmin}^{-1} \mathrm{~cm}^{-2} \mathrm{~cm} \mathrm{H}_{2} \mathrm{O}^{-1}\right)\end{array}$ & $\begin{array}{c}\text { Permeability } \\
\text { Reduction (P-R\%) }\end{array}$ \\
\hline $\begin{array}{c}\text { Sylc bioactive glass }{ }^{\circledR} \\
\text { Powder }\end{array}$ & $\begin{array}{l}100 \%{ }^{1} \\
(0.053)\end{array}$ & $\begin{array}{c}11.2 \%^{\mathrm{a} 2} \\
(0.005)\end{array}$ & 88.8 \\
\hline Sylc bioactive glass $\mathrm{H}_{2} \mathrm{O}$ & $\begin{array}{l}100 \%{ }^{1} \\
(0.028)\end{array}$ & $\begin{array}{l}17.1 \% \text { b2 } \\
(0.006)\end{array}$ & 81.1 \\
\hline $\begin{array}{l}\text { Cavitron }{ }^{\circledR} \text { Prophy-Jet }{ }^{\circledR} \\
\text { sodium bicarbonate }\end{array}$ & $\begin{array}{l}100 \%{ }^{1} \\
(0.052)\end{array}$ & $\begin{array}{c}19.7 \%{ }^{\mathrm{ab} 2} \\
(0.018)\end{array}$ & 80.3 \\
\hline $\begin{array}{l}\text { AIR-flow }{ }^{\circledR} \text { powder } \\
\text { PERIO }\end{array}$ & $\begin{array}{l}100 \%{ }^{1} \\
(0.054)\end{array}$ & $\begin{array}{l}31.2 \%{ }^{\mathrm{c} 2} \\
(0.017)\end{array}$ & 68.8 \\
\hline $\begin{array}{c}\text { Colgate }{ }^{\circledR} \text { Sensitive Pro- } \\
\text { Relief }{ }^{\mathrm{TM}}\end{array}$ & $\begin{array}{l}100 \%{ }^{1} \\
(0.029)\end{array}$ & $\begin{array}{l}30.2 \%^{\mathrm{c} 2} \\
(0.008)\end{array}$ & 69.8 \\
\hline $\begin{array}{c}\text { NUPRO® } \\
\text { NUSolutions }{ }^{\mathrm{TM}} \text { Prophy } \\
\text { Paste. }\end{array}$ & $\begin{array}{l}100 \%{ }^{1} \\
(0.028)\end{array}$ & $\begin{array}{l}33.1 \%{ }^{\mathrm{c} 2} \\
(0.009)\end{array}$ & 66.9 \\
\hline
\end{tabular}

The values of dentine permeability (Lp) are reported as percentage ( $\mathrm{P} \%$ ) and $\mu \mathrm{Lmin}^{-1} \mathrm{~cm}^{-2} \mathrm{~cm} \mathrm{H}_{2} \mathrm{O}-{ }^{1}$. Lp after $37 \% \mathrm{H}_{3} \mathrm{PO}_{4}$ treatment was considered the maximum permeability $(\mathrm{Lp}=100 \%)$. Same letter indicates no differences in columns with different products of the percentage of dentine permeability reduction $-\mathrm{Lp} \%$. Same number indicates no differences in row between PA-etched and products treated-dentine permeability. 

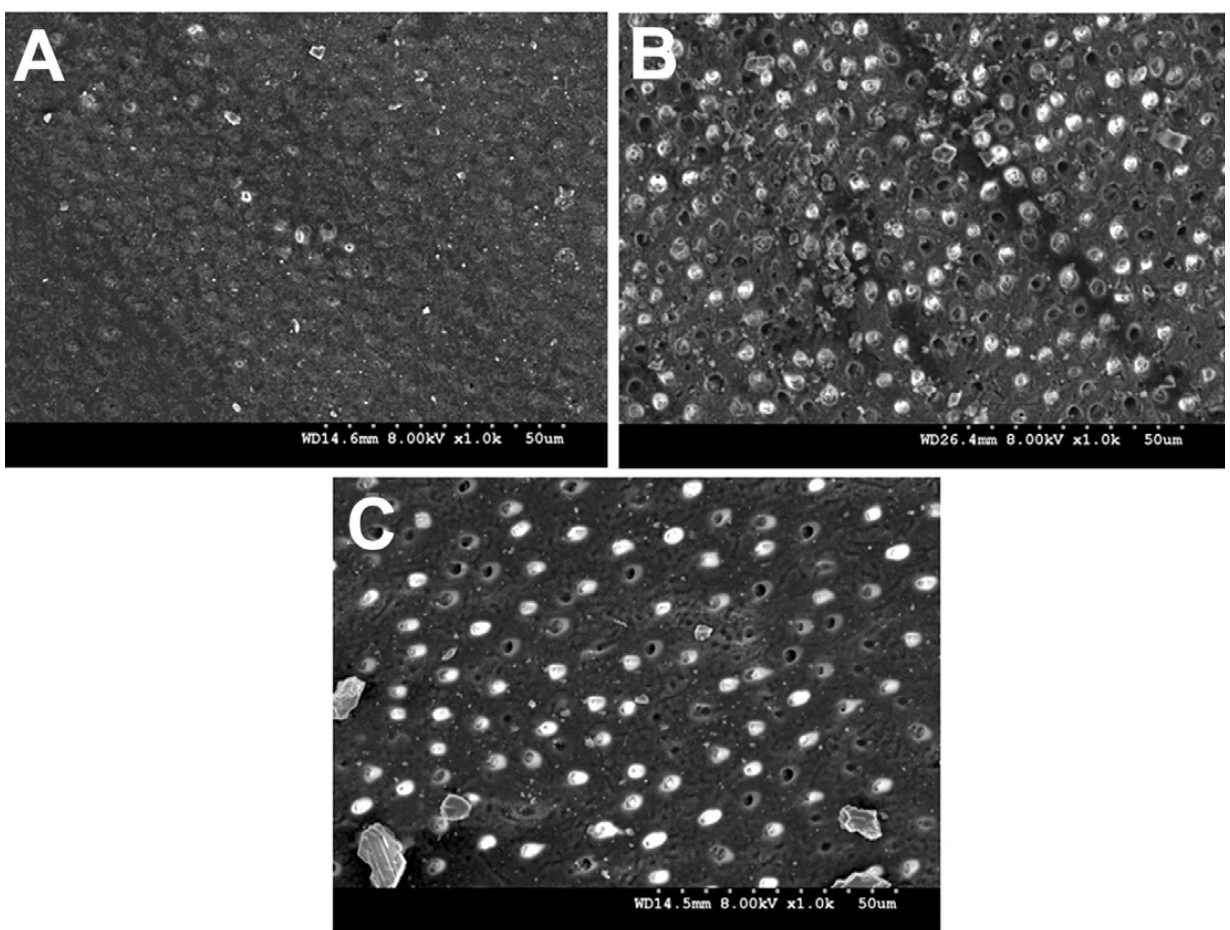

Fig. 3. 1000X SEM micrographs of dentine surfaces treated using the three prophy-pastes tested in this study. Sylc bioactive glass A): the application of this product as prophy paste induced the complete occlusion of most of dentinal tubules leavingthe dentine surface relatively smooth. Nupro Solution Prophy Paste B): the dentine surface appears superficially covered by residual debris that partially or completely occludes the dentinal tubules. Colgate Sensitive Pro-Relief C): the dentine surface appears prevalently smooth with partially occluded dentinal tubules.
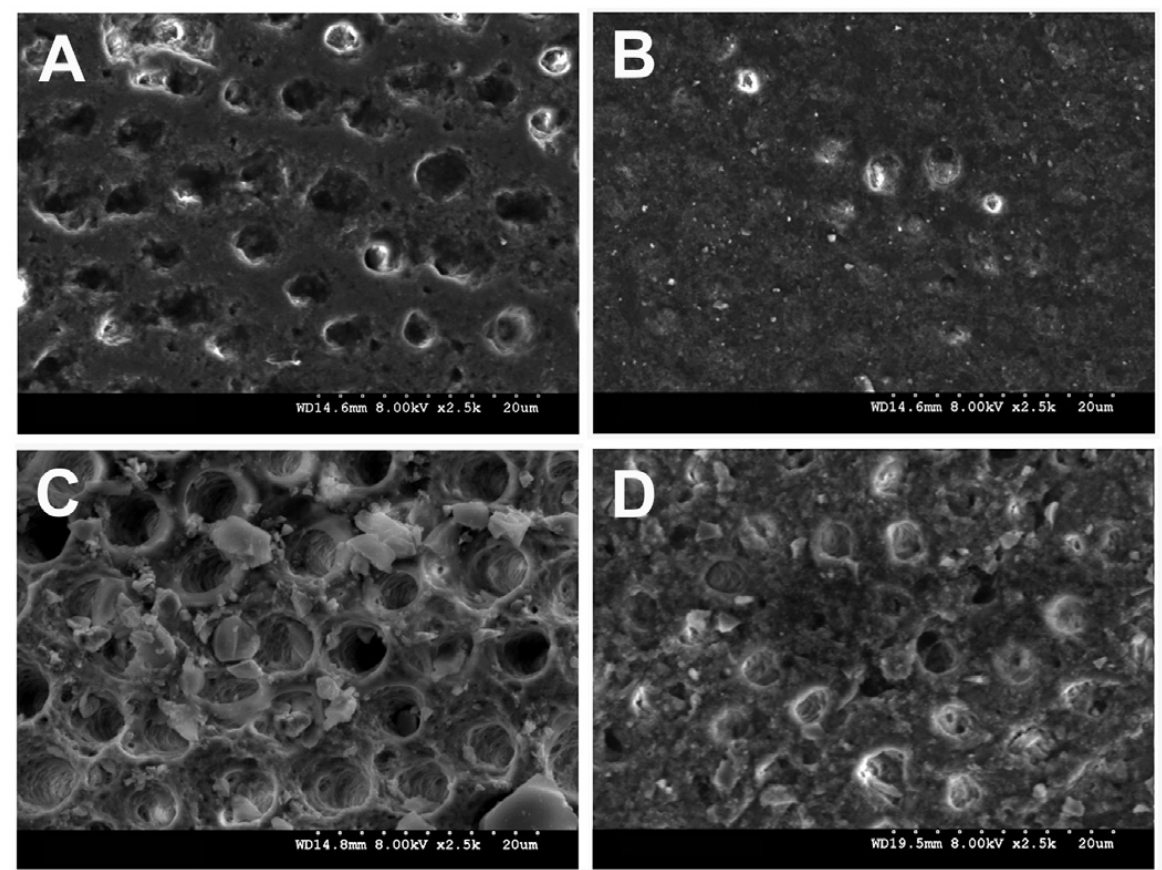

Fig. 4. 2500X SEM higher magnification micrographs of the dentine surface after air-polishing prophylactic procedures using prophy powders and pastes. The pictures A shows the effects of EMS Perio powder on the dentine surface. It is possible to observe that the dentinal tubules are completely or partially open. The pictures B shows the effect Sylc bioactive glass applied with the dental rubber cup induced the complete occlusion of the dentinal tubules leaving a dentine surface relatively smooth. The pictures $\mathbf{C}$ shows how Nupro NovaMin-containing paste created residual debris on the dentine surface. This debris are present also inside the tubules partially or completely occluding them. (D) The Sensitive Pro-Relief paste reduced the diameter and the number of the dentinal tubules. Many tubules can be seen completely occluded. 


\section{Discussion}

The general acceptance of the concept of the hydrodynamic theory postulated by Brännström et al, (8) has resulted in clinical research that it is possible to reduce dentine hypersensitivity by two different approaches: (i) Reduce the ability of the intradental nerves to respond to stimulations $(7,9,21,22)$ (ii) Reduce stimuli-evoked fluid shifts in the dentinal tubules by reducing dentine permeability $(10,23,24)$.

However, the approach to reduce dentine hypersensitivity by enhancing the functional occlusion of dentinal tubules is the only method to achieve the decrease the dentine permeability $(19,24-27)$.

Several desensitizing agents have been employed to accomplish the reduction of the dentine permeability $(10$, $18,25,26,28,29)$. However, little information is available on the effects of prophylactic treatments on dentine permeability. Prophylaxis pastes are commonly used in dentistry to remove dental biofilm and stains. During the PRC prophylaxis process, as well as during air polishing procedures with different prophy-powders, dentine hypersensitivity may increase (18).

Air-polishing has been used for twenty five years for professional tooth cleaning as an alternative to pastes and rubber instruments $(30,31)$. The aim of the air-polishing procedures is the removal of the plaque and of extrinsic discolorations. The prophy-powder commonly used with air-polishing systems is sodium bicarbonate $\left(\mathrm{NaHCO}_{3}\right)$ with particle dimensions in the range of 100 - $200 \mu \mathrm{m}(14,15)$.

Recently, an amino-acid-glycine powder has been thought to be of help in periodontal treatment as well as for air-polishing (17, 32, 33). Whereas, "bioactive glass" prophy-powder constituted by calcium sodium phosphosilicate has been proposed for therapeutic and bioactive air-polishing procedures due to its capacity to react with saliva and deposit hydroxycarbonate apatite (HCA) $(34,35)$. The results of this study demonstrated that Sylc bioactive glass and Prophy-Jet sodium bicarbonate powders were the most effective in reducing the dentine permeability of PA-etched middle dentine at 4 bar of pressure (Table 1).

However, air-polishing procedures performed using Sylc bioactive glass ( $\mathrm{P} \% 11.2 \%$ ) showed statistically higher permeability reduction compared to Prophy-Jet sodium bicarbonate ( $\mathrm{P} \% 19.7 \%$ ) used at 4 bar of pressure in middle dentine. Sauro et al, (18) have recently shown that when these two air-polishing powders were used at higher pressure (i.e. 5 bar), no statistical difference, in terms of dentine permeability reduction, could be observed between the two materials. The SEM analysis suggests that this difference may be attributed to the lower pressure parameters used in this study which were probably insufficient for the sodium bicarbonate to create a compact smear layer on the exposed dentine.
Lower dentine permeability reduction was observed in the group of air-polished specimens with EMS Perio powder (-68.8). These results may be due to the absence of a consistent smear layer deposited on the surface but only to the presence dentinal tubules completely or partially open (Fig 2.D, 4.A). On the contrary, the use of Sylc bioactive glass and Prophy-Jet sodium bicarbonate formed a smear layer (Fig. 2.B, 2.C) that covered the exposed PA-treated dentine (Fig. 2.A).

Recent studies have shown that glycine-based powders have lower abrasiveness compared to other bicarbonatebased prophy-powders $(32,36)$. Indeed, this type of softer prophy-powder has been developed to be safely applied subgingivally during supra- and subgingival deplaquing (17). Nevertheless, the efficacy of glycinebased powders as dentine desensitizing seems to be inferior to that of the bioactive glass and sodium bicarbonate powders. Although the dentine permeability results of this study have been obtained in middle dentine and with a lower delivering pressure (i.e. 4 bar), they offer a wider view on the desensitizing capability of these prophylactic products when correlated to those of Sauro et al, (18) who tested the same materials tested on deep dentine at 5 bar of pressure. It is now possible to affirm that higher delivering pressure is an important parameter to consider when using sodium bicarbonate, but not when using Sylc bioactive glass. On the contrary, the different number of tubules and the reduced tubular fluid flow seem to be factors not primarily important to the performance of the prophy powders in reducing the dentine permeability.

The results are supported by the SEM investigation which showed that Sylc bioactive glass and ProphyJet sodium bicarbonate were able to create a consistent smear layer after their application on exposed dentine (Fig. 2.B) whereas, the air polishing performed with ESM Perio powder created a thin smear layer on the dentine surface and only some powder/smear plugs inside the tubule (Fig. 4.A).

It has been recently demonstrated that non-surgical treatments of scaling and root-planing performed using hand curette were able to create a more compact and multilayered acid resistant smear layer than that using an ultrasonic device which created a thin smear layer on the root dentine surface (5). The authors speculate on the concept of "resistance of the smear layer morphology" which is based on the fact that a highly porous smear layer is less effective to keep dentinal tubules occluded under acid challenge (5). Our hypothesis is that the application Sylc bioactive glass creates a smear layer much more compact and a bioactive intimate contact with the exposed dentine. Moreover, the bioactive characteristics of this material and the compact smear layer created during prophylactic procedures might offer the possibility of HA-deposition (remineralization) 
when exposed to fluids containing calcium and phosphate, such as saliva and tubular fluid (35-37).

Different results were observed when the specimens were treated with the prophy-pastes applied using PRC. Although most of the prophy-pastes used in this study were able to statistically reduce the dentine permeability of PA-etched dentine specimens, no more than $70 \%$, of dentine permeability reduction was obtained. It is important to consider that several in vivo $(19,28,36)$ and in vitro $(20,38-41)$ studies consider a gold standard treatment for dentine hypersensitivity the use oxalates which decrease dentine permeability by about $90 \%$ by creating acid-resistant calcium oxalate crystals both on the dentine surface and inside dentinal tubules.

The prophy-pastes applied with the PRC resulted in less dentine permeability reduction and in the reduced capacity to occlude the dentinal tubules compared to those of air-polished specimens (i.e. Sylc bioactive glass, Prophy-Jet sodium bicarbonate) also when applied in middle dentine. However, when Sylc bioactive glass was applied using a dental rubber cup it was possible to obtain a statistically higher dentine permeability reduction $(-81.8 \%)$ compared to the other prophy-pastes used in this study. Thus, this may be an interesting alternative, in terms of dentine permeability reduction, to the current prophy-pastes.

The specimens treated with Colgate Sensitive Pro-Relief and NUPRO Solution Prophy-paste showed dentine permeability reduction of $-69.8 \%$ and $-66.9 \%$ respectively; no statistical difference was observed between these two commercial prophy-pastes. The SEM investigation showed that when Colgate Sensitive Pro-Relief was applied on exposed dentinal tubules only partial occlusion of the tubules was achieved. The most important observation in these specimens was the reduction of the lumen of the dentinal tubules. These results are in contrast with those of Petrou et al, (42) who reported recently that the application of Colgate Sensitive Pro-Relief was able to completely occlude the dentinal tubules. The differences may be attributed to the fact that in our study this prophypaste was applied only once for 30s, while the authors of that paper obtained the maximum occlusion of the tubule and of the highest dentine permeability reduction after higher number of treatments (5 applications). The same observation may be applied to the use of NUPRO ${ }^{\circledR} \mathrm{NU}-$ Solutions ${ }^{\mathrm{TM}}$, a Prophy Paste containing NovaMin ${ }^{\circledR}$ indicated for the immediate treatment of dentine hypersensitivity. Indeed, although NovaMin ${ }^{\circledR}$ is a calcium sodium phosphosilicate bioactive glass with osteoinductive properties and forms carbonate hydroxyapatite when used in oral health care, our SEM investigation showed that the application of this product only superficially covered the exposed dentine surface with residual debris. This debris was found inside the dentinal tubules which only partially occluding them.
In conclusion, prophylactic procedures performed in middle dentine at lower working pressure are able to statistically reduce the dentine permeability and occlude the dentinal tubules. However, in situations of different morphological and pressure working parameters, the use of Sylc bioactive glass proved to be a suitable prophy-powder for dental air-polishing able to completely occlude the exposed dentinal tubules and reduce the dentine permeability.

\section{References}

References with links to Crossref - DOI

1. von Troil B, Needleman I, Sanz M. A systematic review of the prevalence of root sensitivity following periodontal therapy. J Clin Periodontol. 2002;29 Suppl 3:173-7.

2. Crespi R, Barone A, Covani U. Histologic evaluation of three methods of periodontal root surface treatment in humans. J Periodontol. 2005;76:476-81.

3. Fiocchi MF, Moretti AJ, Powers JM, Rives T. Treatment of root sensitivity after periodontal therapy. Am J Dent. 2007;20:217-20.

4. Kawashima H, Sato S, Kishida M, Ito K. A comparison of root surface instrumentation using two piezoelectric ultrasonic scalers and a hand scaler in vivo. J Periodontal Res. 2007;42:90-5.

5. Sauro S, Mannocci F, Watson TF, Piemontese M, Sherriff M, Mongiorgi R. The influence of soft acidic drinks in exposing dentinal tubules after non-surgical periodontal treatment: a SEM investigation on the protective effects of oxalate-containing phytocomplex. Med Oral Patol Oral Cir Bucal. 2007;12:E542-8.

6. Pashley DH, Matthews WG, Zhang Y, Johnson M. Fluid shifts across human dentine in vitro in response to hydrodynamic stimuli. Arch Oral Biol. 1996;41:1065-72.

7. Addy M. Tooth brushing, tooth wear and dentine hypersensitivity-are they associated? Int Dent J. 2005;55:261-7.

8. Brännstrom M, Lindén LA, Johnson G. Movement of dentinal and pulpal fluid caused by clinical procedures. J Dent Res. 1968;47:67982.

9. Addy M, Dowell P. Dentine hypersensitivity-a review. Clinical and in vitro evaluation of treatment agents. J Clin Periodontol. 1983;10:351-63.

10. Pashley DH. Dentin permeability, dentin sensitivity, and treatment through tubule occlusion. J Endod. 1986;12:465-74.

11. Pashley DH. Dentin permeability and dentin sensitivity. Proc Finn Dent Soc.1992;88 Suppl 1:31-7.

12. Jost-Brinkmann PG. The influence of air polishers on tooth enamel. An in-vitro study. J Orofac Orthop. 1998;59:1-16.

13. Pikdoken ML, Ozcelik C. Severe enamel abrasion due to misuse of an air polishing device. Int J Dent Hyg. 2006;4:209-12.

14. Banerjee A, Hajatdoost-Sani M, Farrell S, Thompson I. A clinical evaluation and comparison of bioactive glass and sodium bicarbonate air-polishing powders. J Dent. 2010;38:475-9.

15. Tada K, Kakuta K, Ogura H, Sato S. Effect of particle diameter on air polishing of dentin surfaces. Odontology. 2010;98:31-6.

16. Jepsen S, Ayna M, Hedderich J, Eberhard J. Significant influence of scaler tip design on root substance loss resulting from ultrasonic scaling: a laserprofilometric in vitro study. J Clin Periodontol. 2004;31:1003-6.

17. Petersilka G. Re: "Subgingival plaque removal using a new airpolishing device". Moëne R, Décaillet F, Andersen E, Mombelli A. (J Periodontol 2010;81:79-88.). J Periodontol. 2010;81:962-3.

18. Sauro S, Watson TF, Thompson I. Dentine desensitization induced by prophylactic and air-polishing procedures: an in vitro dentine permeability and confocal microscopy study. J Dent. 2010;38:41122.

19. Orchardson R, Gillam DG. The efficacy of potassium salts as agents for treating dentin hypersensitivity. J Orofac Pain. 2000;14:919.

20. Sauro S, Gandolfi MG, Prati C, Mongiorgi R. Oxalate-containing 
phytocomplexes as dentine desensitisers: an in vitro study. Arch Oral Biol. 2006;51:655-64.

21. Gillam DG, Orchardson R. Advances in the treatment of root dentin sensitivity: mechanisms and treatment principles. Endodontic Topics 2006;13:13-33.

22. Noparatkailas S, Wanachantararak S, Vongsavan N, Matthews B. The effect of applying potassium chloride solutions at atmospheric pressure on the sensitivity of dentine in man. Arch Oral Biol. 2009;54:50-4.

23. Bekes K, Schmelz M, Schaller HG, Gernhardt CR. The influence of application of different desensitisers on root dentine demineralisation in situ. Int Dent J. 2009;59:121-6.

24. Hamlin D, Williams KP, Delgado E, Zhang YP, DeVizio W, Mateo LR. Clinical evaluation of the efficacy of a desensitizing paste containing $8 \%$ arginine and calcium carbonate for the in-office relief of dentin hypersensitivity associated with dental prophylaxis. Am J Dent. 2009;22 Spec A:16A-20A.

25. Pashley DH, Tao L, Boyd L, King GE, Horner JA. Scanning electron microscopy of the substructure of smear layers in human dentine. Arch Oral Biol. 1988;33:265-70.

26. Pashley DH. Mechanisms of dentin sensitivity. Dent Clin North Am. 1990;34:449-73.

27. Rusin RP, Agee K, Suchko M, Pashley DH. Effect of a new desensitizing material on human dentin permeability. Dent Mater. 2010;26:600-7.

28. Muzzin KB, Johnson R. Effects of potassium oxalate on dentin hypersensitivity in vivo. J Periodontol. 1989;60:151-8.

29. Wang Z, Sa Y, Sauro S, Chen H, Xing W, Ma X, et al. Effect of desensitising toothpastes on dentinal tubule occlusion: a dentine permeability measurement and SEM in vitro study. J Dent. 2010;38:40010.

30. Willmann DE, Norling BK, Johnson WN. A new prophylaxis instrument: effect on enamel alterations. J Am Dent Assoc. 1980;101:923-5.

31. Jost-Brinkmann PG. The influence of air polishers on tooth enamel. An in-vitro study. J Orofac Orthop. 1998;59:1-16.

32. Petersilka GJ, Steinmann D, Häberlein I, Heinecke A, Flemmig TF. Subgingival plaque removal in buccal and lingual sites using a novel low abrasive air-polishing powder. J Clin Periodontol. 2003;30:328-33.

33. Petersilka G, Faggion CM Jr, Stratmann U, Gerss J, Ehmke B, Haeberlein I, et al. Effect of glycine powder air-polishing on the gingiva. J Clin Periodontol. 2008;35:324-32.

34. Hench LL, Andersson Ö. Bioactive glasses. In: Introduction to bioceramics. Hench LL, Wilson J, editors. Singapore: World Scientific; 1993:45-47.

35. Burwell AK, Litkowski LJ, Greenspan DC. Calcium sodium phosphosilicate (NovaMin): remineralization potential. Adv Dent Res. 2009;21:35-9.

36. Kahl M, Haase E, Kocher T, Rühling A. Clinical effects after subgingival polishing with a non-aggressive ultrasonic device in initial therapy. J Clin Periodontol. 2007;34:318-24.

37. Zero DT, Lussi A. Etiology of enamel erosion: intrinsic and extrinsic factors. In: Addy M, Embery G, Edgar WM, Orchardson $\mathrm{R}$, editors. Tooth wear and sensitivity. London: Martin-Dunitz; 2000;11:121-39.

38. Kerns DG, Scheidt MJ, Pashley DH, Horner JA, Strong SL, Van Dyke TE. Dentinal tubule occlusion and root hypersensitivity. J Periodontol. 1991;6:421-8.

39. Mongiorgi R, Tateo F, Monti S, Prati C, Bertocchi G. Calcium oxalate smear layer: mineralogical and crystallographic study. Boll Soc Ital Biol Sper. 1992;68:99-103.

40. Gillam DG, Mordan NJ, Sinodinou AD, Tang JY, Knowles JC, Gibson IR. The effects of oxalate-containing products on the exposed dentine surface: an SEM investigation. J Oral Rehabil. 2001;28:103744.

41. Suge T, Kawasaki A, Ishikawa K, Matsuo T, Ebisu S. Ammonium hexafluorosilicate elicits calcium phosphate precipitation and shows continuous dentin tubule occlusion. Dent Mater. 2008;24:192-8.
42. Petrou I, Heu R, Stranick M, Lavender S, Zaidel L, Cummins D, et al. A breakthrough therapy for dentin hypersensitivity: how dental products containing $8 \%$ arginine and calcium carbonate work to deliver effective relief of sensitive teeth. J Clin Dent. 2009;20:23-31.

\section{Acknowledgments}

This study was supported by the Department of Health via the National Institute for Health Research (NIHR) comprehensive Biomedical Research Centre award to Guy's \& St Thomas' NHS Foundation Trust in partnership with King's College London and King's College Hospital NHS Foundation Trust and OSspray Ltd. Company, London, UK. 